\title{
Protótipo para análise da qualidade de gasolina tipo $C$ comum utilizando sensores de gás tipo semicondutor
}

\section{Luiz Antonio Pimentel Cavalcanti}

Instituto Federal de Educação. Ciência e Tecnologia da Bahia. Campus de Paulo Afonso. Rua Marcondes Ferraz, 200. Bairro General Dutra. Paulo Afonso-BA (CEP 48607-000). E-mail: luiz.cavalcanti@ifba.edu.br.

Resumo. 0 controle da qualidade de combustíveis é um elemento de notável importância para o desenvolvimento econômico e ambiental de um país. Realizar esta análise de forma rápida e eficiente é um anseio crescente da sociedade, e acarreta a necessidade do desenvolvimento de tecnologias que possibilitem essa melhoria. 0 presente trabalho teve por objetivo avaliar o desempenho de sensores semicondutores em detectar adulteração da gasolina tipo C comum. Desenvolveu-se um protótipo compostos de uma câmara de gás onde foram fixados sensores da família MQ's (MQ2, MQ3, MQ4, MQ6, MQ7 e MQ9) e dois sensores DHT11 para medição de temperatura e umidade. 0 protótipo foi interligado a uma plataforma de microcontrolador Arduino e foram formuladas adulterações em amostras de gasolina tipo C comum nas proporções de $5 \%, 10 \%, 20 \%, 30 \%$ e $50 \%(\mathrm{~m} / \mathrm{m})$ de etanol anidro em base gravimétrica. As curvas de resposta dos sensores semicondutores demonstraram que o desempenho do protótipo foi satisfatório em identificar qualitativamente a adulteração do combustível.

Palavras-chave: Adulteração; Qualidade dos combustíveis; Sensores semicondutores.

\section{Abstract. Prototype for analysis of the quality of common type $C$ gasoline using semiconductor type gas sensors. Control of fuel quality is an factor of considerable importance for the economic and environmental development of a country. Accomplish out this analysis quickly and efficiently is a growing yearning for society, and requires the development of technologies that enable this improvement. The present work had the objective of evaluating the acting of semiconductor sensors in detecting adulteration of the common type $\mathrm{C}$ gasoline. A prototype composed of a drip chamber was developed when the MQ family sensors (MQ2, MQ3, MQ4, MQ6, MQ7 and MQ9) and two DHT11 sensors were set for temperature and humidity measurement. The prototype was interconnected to a microcontroller platform and was formulated in 5 units of $10 \%$, $10 \%, 20 \%, 30 \%$ and $50 \%(\mathrm{w} / \mathrm{w})$ of anhydrous ethanol on a gravimetric basis. The response curves of the semiconductor}

Recebido:

30/12/2018

Aceito:

29/03/2019

Publicado:

30/04/2019

Acesso aberto

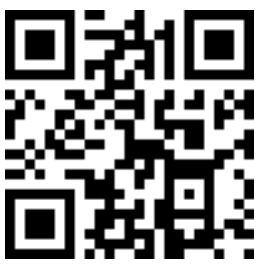

ORCID

(D) 0000-0003-4932-9387 Luiz Antonio Pimentel Cavalcanti 
sensors demonstrated that the performance of the prototype was satisfactory in qualitatively identifying the fuel adulteration.

Keywords: Adulteration; Fuel Quality; Semiconductor sensors.

\section{Introdução}

A gasolina combustível produto resultante da destilação do petróleo bruto, tem atualmente ocupado destaque incontestável como o principal combustível comercializado para motores ciclo Otto. A sua composição pode variar de acordo com o método de obtenção e componentes de hidrocarbonetos do petróleo, sendo composta basicamente por hidrocarbonetos parafínicos e naftênicos de 4 a 12 átomos de carbono. Caracterizando-se como um dos produtos mais leves obtidos na destilação do petróleo bruto (Freitas, 2017).

Devido sua importância como combustível em veículos automotivos no Brasil, a gasolina, tem sido alvo de adulterações que comprometem a qualidade do combustível, diminui a vida útil do motor, prejudica o meio ambiente devido às emissões provenientes da combustão incompleta e acarreta prejuízos financeiros para o consumidor final. Tais adulterações ocorrem em sua maioria durante o transporte da carga ou mesmo no próprio posto de combustível. 0 programa de monitoramento da qualidade da Agência Nacional do Petróleo, Gás Natural e Biocombustíveis (ANP), fiscaliza postos de combustíveis em todo território visando a manutenção da conformidade do combustível para o consumidor final (Hygino et al., 2016).

0 consumidor, atualmente, pode verificar a qualidade da gasolina comercializadas em postos de combustíveis por um procedimento simples denominado "teste da proveta", contudo na maioria dos casos o cliente não tem conhecimento que o posto tem obrigação de realizar o teste sempre que solicitado, ou mesmo não compreende como o teste funciona. Testes com dispositivos eletrônicos poderiam assumir espaço no mercado, devido a sua praticidade, confiabilidade e demandar pequena quantidade de amostra para realização do experimento (Campos, 2017).

Pode-se implementar um sistema composto por um conjunto de sensores não específicos que são tratados com uma variedades de materiais quimicamente sensíveis. Os sensores que são dispostos no sistema devem responder de maneira distinta quando são expostos a diferentes substâncias e a escolha de um bom conjunto de sensores, geralmente, produz um padrão característico de resposta para determinada substância ou misturas delas (Reitenbach, 2016).

0 presente trabalho teve por objetivo avaliar o comportamento de sensores de gases semicondutores na presença de um combustível líquido (gasolina comum tipo C) de modo que possa distinguir as amostras entre adulteradas e não adulteradas.

\section{Materiais e métodos}

Os sensores MQ2, MQ3, MQ4, MQ6, MQ7, MQ9 e DTT11 foram adquiridos em casas de produtos eletrônicos na cidade de Aracaju. A amostra de gasolina Tipo C comum, $5 \mathrm{~L}$, foi adquirida em posto de combustível localizado na Cidade de Paulo Afonso, Estado da Bahia. 0 etanol anidro, marca SIGMA-ALDRICH, pureza 99,9\%, utilizado para adulteração do combustível e vidrarias utilizadas no experimento foram cedidos pelo laboratório de química do Instituto Federal de Educação, Ciência e Tecnologia da Bahia (IFBA), Campus Paulo Afonso. 


\section{Construção do protótipo}

A câmara de gás foi desenvolvida com o propósito de criar um ambiente de volume controlado de fluxo gasoso para a calibração dos sensores e caracterização dos combustíveis a serem analisados.

0 sistema consiste em uma entrada e uma saída de gás, onde em sua tampa, acomoda-se uma interligação metálica tipo $\mathrm{T}$ com duas válvulas de retenção. A câmara de gás é um recipiente hermético, cilíndrico de vidro e possui um volume útil de $500 \mathrm{~cm}^{3}$, adaptado a partir de um frasco reagente disponível no laboratório de química, sendo este, dimensionada para acomodar seis sensores gás da família MQs e um sensor de temperatura e umidade da família DHT.

Após a perfuração dos orifícios na câmara de gás com broca diamantada para perfurar vidro com $12 \mathrm{~mm}$ de diâmetro, foram fixados os sensores com cola de alta temperatura, havendo a preocupação na vedação visando impedir os possíveis vazamentos dos vapores. Os sensores foram fixados na forma circular, ou seja, ao redor da câmara de gás com espaçamentos aproximado de $30 \mathrm{~mm}$ (Figura 1), e de forma que conduzam as variações elétricas do nariz eletrônico para o Arduino que é responsável pela leitura dos sinais que são enviados ao computador.

Logo que foi definido que seria utilizada a placa Arduino como sistema de processamento de dados, foi necessário desenvolver um circuito capaz de adquirir os dados dos sensores com menor interferência possível, elencando os componentes necessários para tal. Com auxílio de um software de prototipagem de circuitos impressos, desenvolveram-se diversos formatos de circuitos para uma futura análise da melhor conformação. Sendo determinado o melhor formato, o circuito foi transferido para uma placa de prototipagem para que, a posteriori, pudessem ser soldados os componentes eletrônicos e conectores.

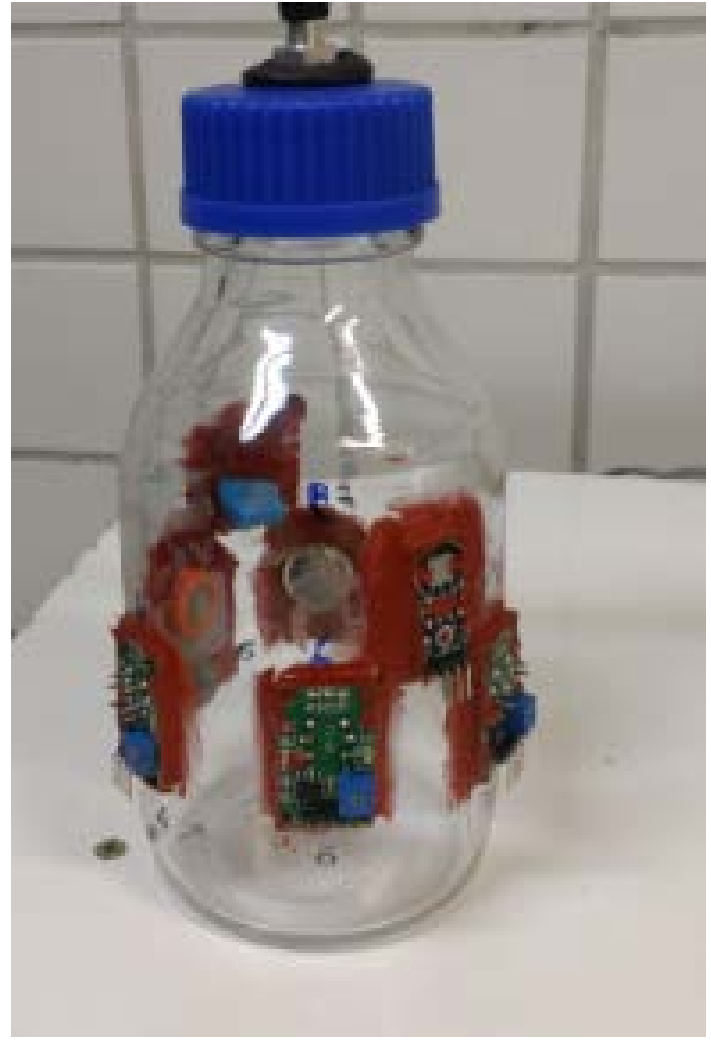

Figura 1. Câmara de gás.

Realizadas todas as soldas, foram realizados testes iniciais de continuidade para verificar a qualidade das conexões entre os componentes e as trilhas do circuito, a fim de corrigir qualquer falha antes da energização. Utilizando um software de aquisição de dados, associado a uma programação que foi inserida no microcontrolador, foi possível iniciar os testes reais e submeter os sensores às amostras de combustíveis, verificando seu comportamento.

\section{gasolina}

Testes de adulteração da

A amostra de gasolina tipo C comum foi submetida ao teste da proveta para determinação do teor de etanol anidro presente na mesma. Com o auxílio de uma proveta de $200 \mathrm{~mL}$, aferiu-se 50 $\mathrm{mL}$ da amostra de gasolina e adicionouse posteriormente $50 \mathrm{~mL}$ de uma solução de $\mathrm{NaCl}$ a $10 \%(\mathrm{~m} / \mathrm{v})$, homogeneizou-se vigorosamente e a mistura foi mantida em repouso por 15 minutos. Após a 
separação das fases foram efetuados cálculos para determinação do teor de etanol anidro presente na gasolina.

\section{Formulação das adulterações}

A formulação das amostras de gasolina adulteradas adotou método gravimétrico visando à minimização de erros devido à dilatação volumétrica do líquido e da vidraria. Para isso foi medida em laboratório a massa específica da amostra de gasolina e de etanol anidro com auxílio de um picnômetro. Foram formuladas adulterações com etanol em proporções de $5 \%, 10 \%, 20 \%, 30 \%$ e $50 \%$ (Figura 2).

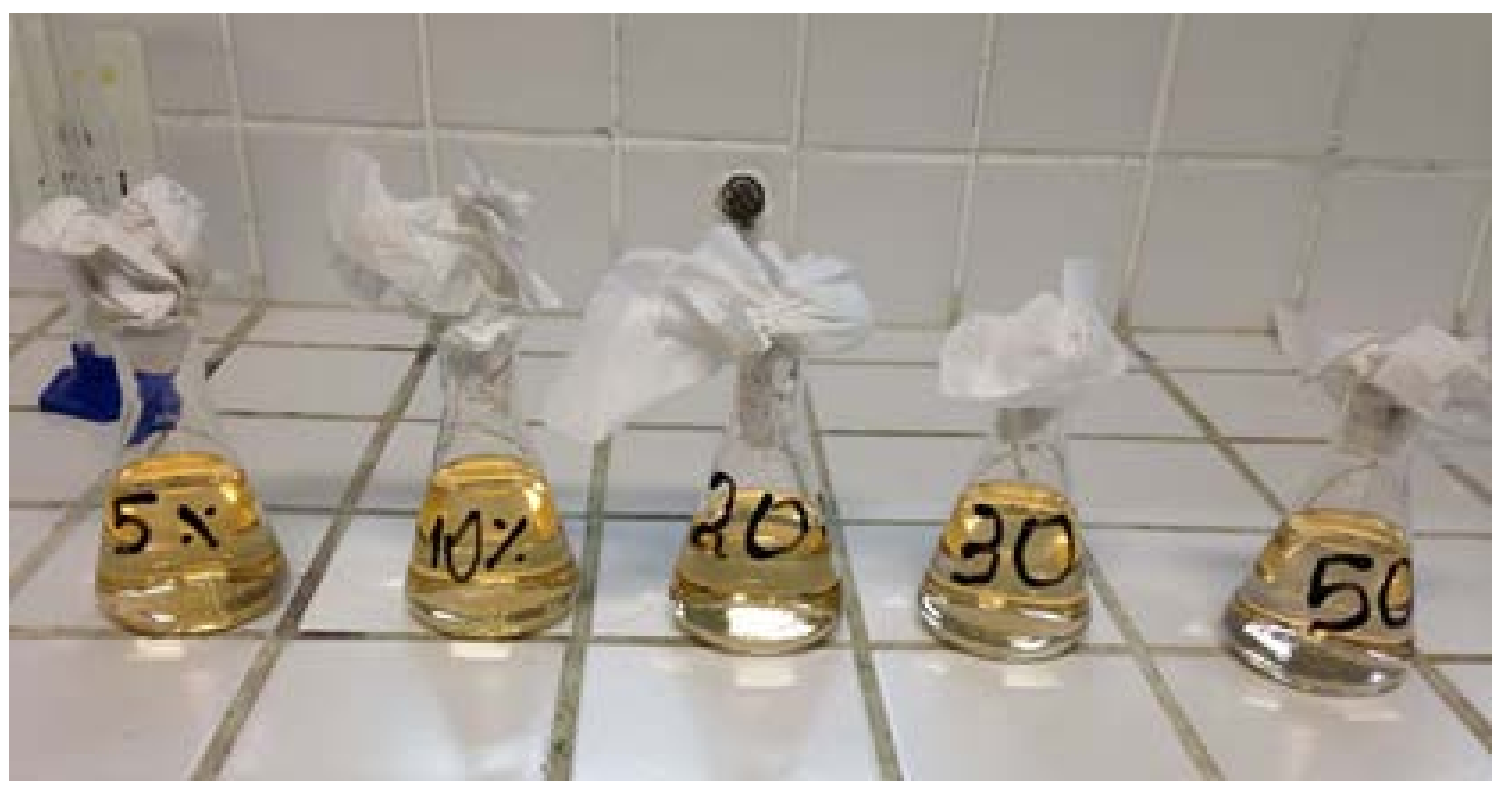

Figura 2. Amostras de gasolina adulteradas.

\section{Resultados e discussão}

Circuito de aquisição de dados Idealizado e confeccionado o circuito responsável pela aquisição dos dados e ligada a alimentação deste, foi realizada a medição de tensão com um voltímetro em diferentes pontos, e foi verificado que todos os componentes do circuito estavam sendo alimentados, a conformação final do circuito é apresentada na Figura 3. Também foi atestada a ausência de curto circuito entre as soldas que foram feitas significativamente próximas umas às outras.

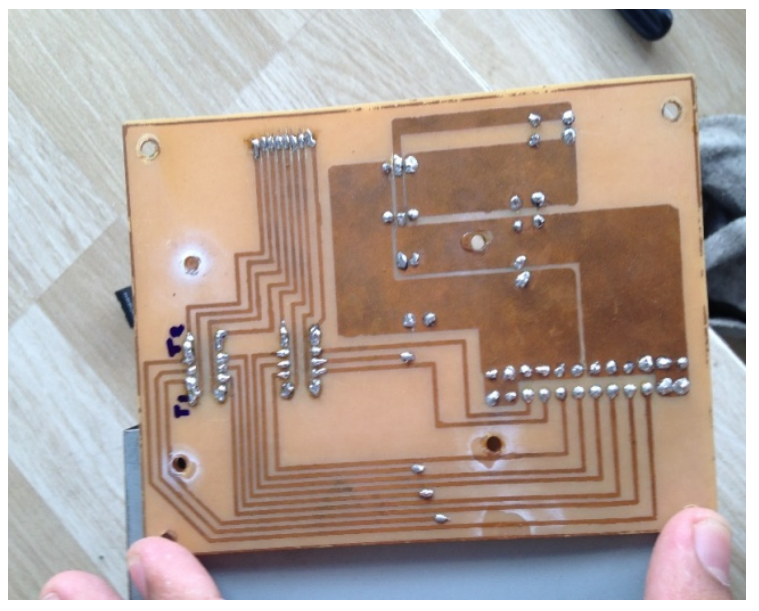

Figura 3. Trilhas do circuito de aquisição de dados. 


\section{Programação e processamento}

A programação inserida na placa Arduino foi capaz de traduzir a variação de tensão dos sensores, de 0 a 5 Volts, em um sinal digital que varia em 0 e 1023 .

O software Elipse SCADA utilizando o sinal digital de saída do
Arduino, representa-o em gráficos dinâmicos que exibem uma leitura a cada segundo, exportando esses dados para uma planilha do Excel que os armazena. A Figura 4 exibe a interface do software Elipse SCADA.

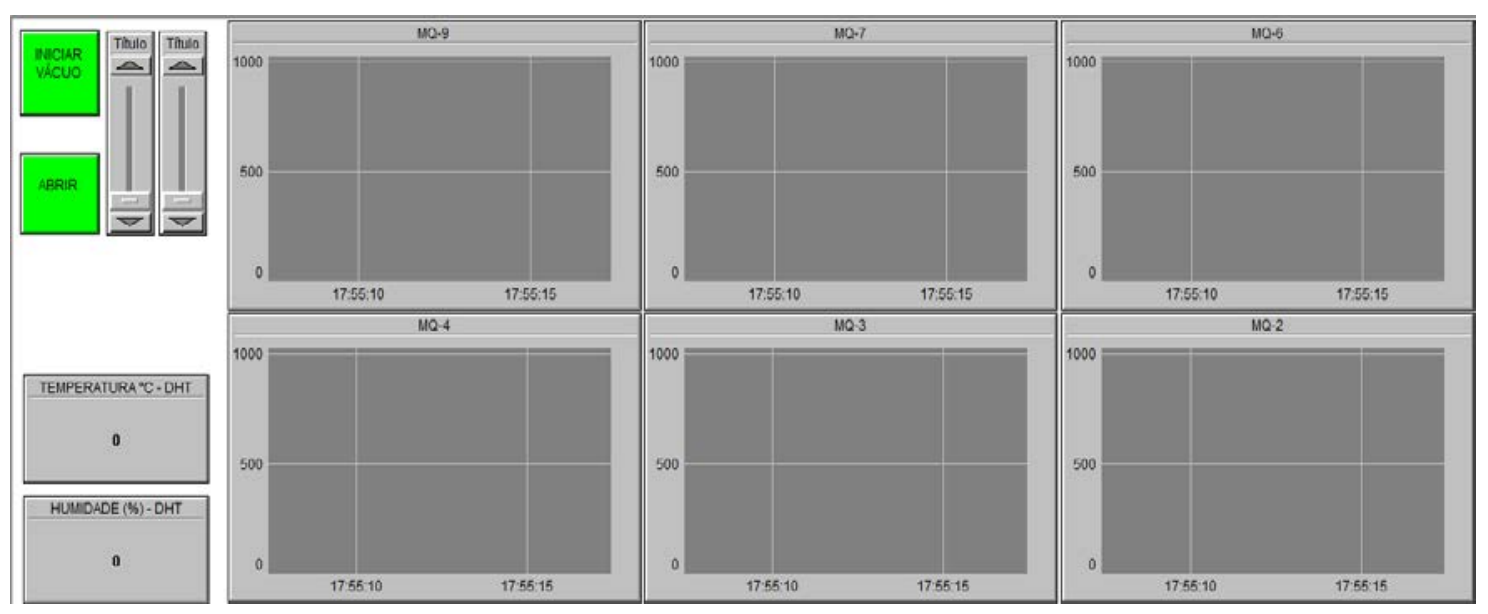

Figura 4. Tela do programa Elipse SCADA.

\section{Teste de conexão}

Com o hardware e o software prontos, conectou-se os sensores ao Arduino e este ao computador, verificando assim uma comunicação satisfatória entre os sensores e o microcontrolador, obtendo leitura em todos os gráficos dos sensores e constatando-se que os dados estavam sendo exportados para a planilha.

\section{Teste com combustíveis adulterados}

0 teste da proveta realizado com a amostra de gasolina indicou que o teor de etanol anidro na mistura era de $25 \%$ dentro do limite estabelecido pela Resolução ANP no 40/2013 (ANP, 2013). Partindo das amostras de adulterações formuladas em laboratório, conforme apresentado na seção de metodologia e o protótipo em sua conformação inicial foram realizados os primeiros testes.

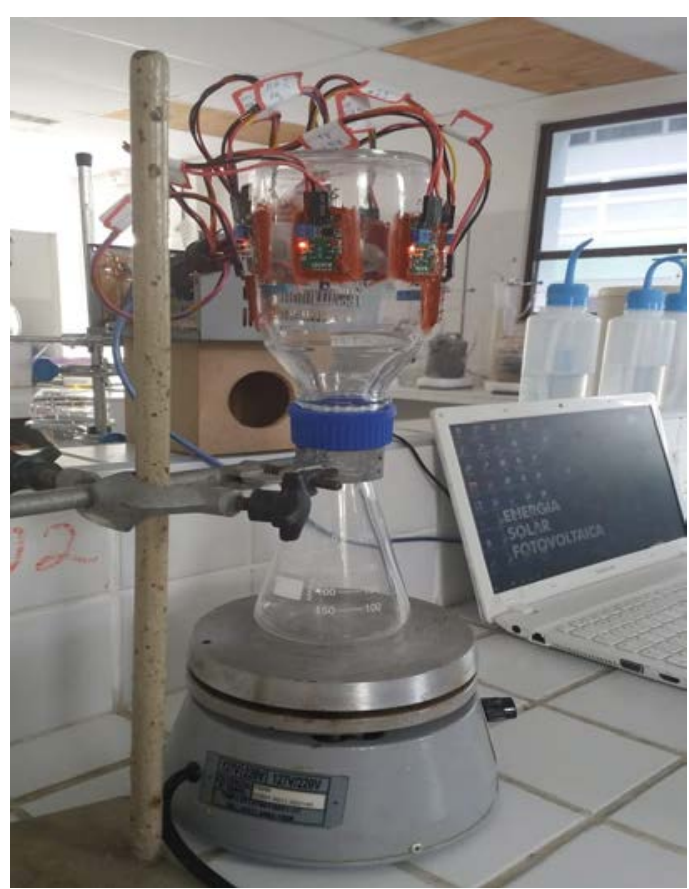

Figura 5. Protótipo após modificações. 
Os resultados apresentaram em suas curvas flutuações inconsistentes demonstrando que a configuração do protótipo gerava perturbações devido a um fluxo turbulento de gás no interior da câmara de captação. Tal efeito era causado devido ao transporte de fluido ser realizado com uma bomba a vácuo.

Foi realizado uma adaptação no protótipo onde o combustível inserido em um Erlenmeyer de $250 \mathrm{~mL}$ e ajustouse a tampa da câmara de gás por uma perfuração conforme apresentado na Figura 5. A agitação da amostra de combustível foi realizada em chapa aquecedora dotada de agitação, aproveitou-se a alta volatilidade da gasolina que se transferia espontaneamente para a câmara de gás, os vapores formados tiveram sua presença captada pelos sensores instalados no protótipo.

Com o sistema de detecção de gases em funcionamento, foi necessário criar amostras de gasolina com diversos níveis de adulteração de álcool, e verificar se os sensores detectariam a diferença entre as amostras. Os resultados desses testes estão apresentados nas Figuras 6 e 7.

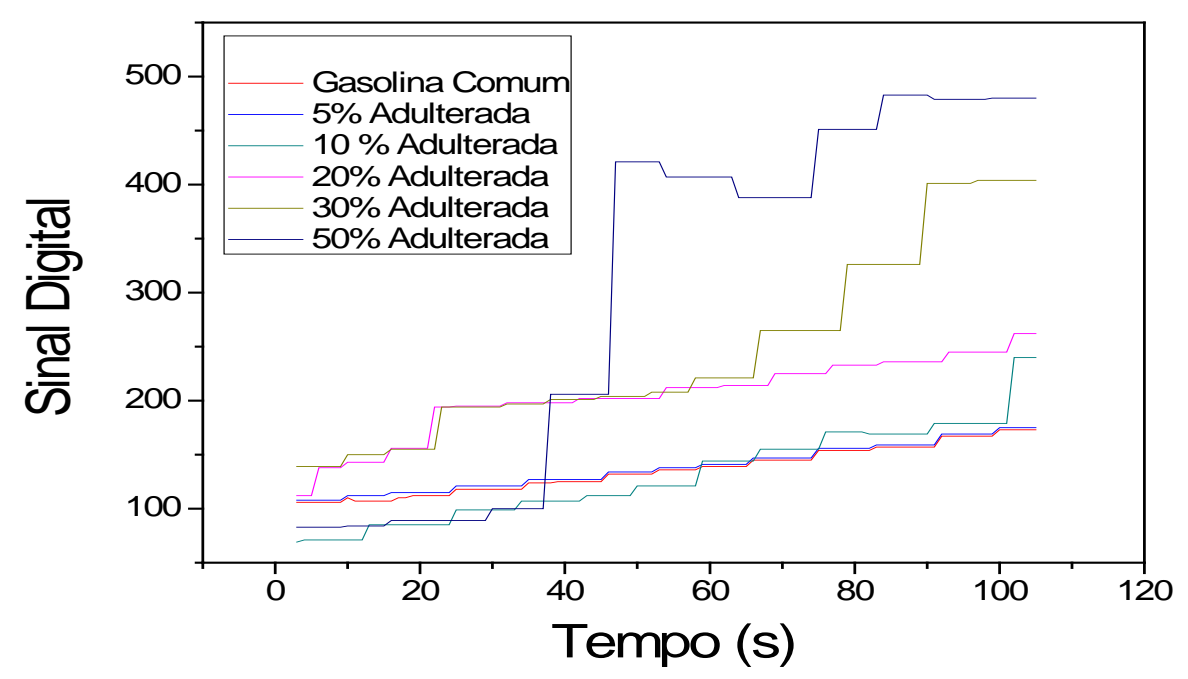

Figura 6. Leitura do sensor MQ-2.

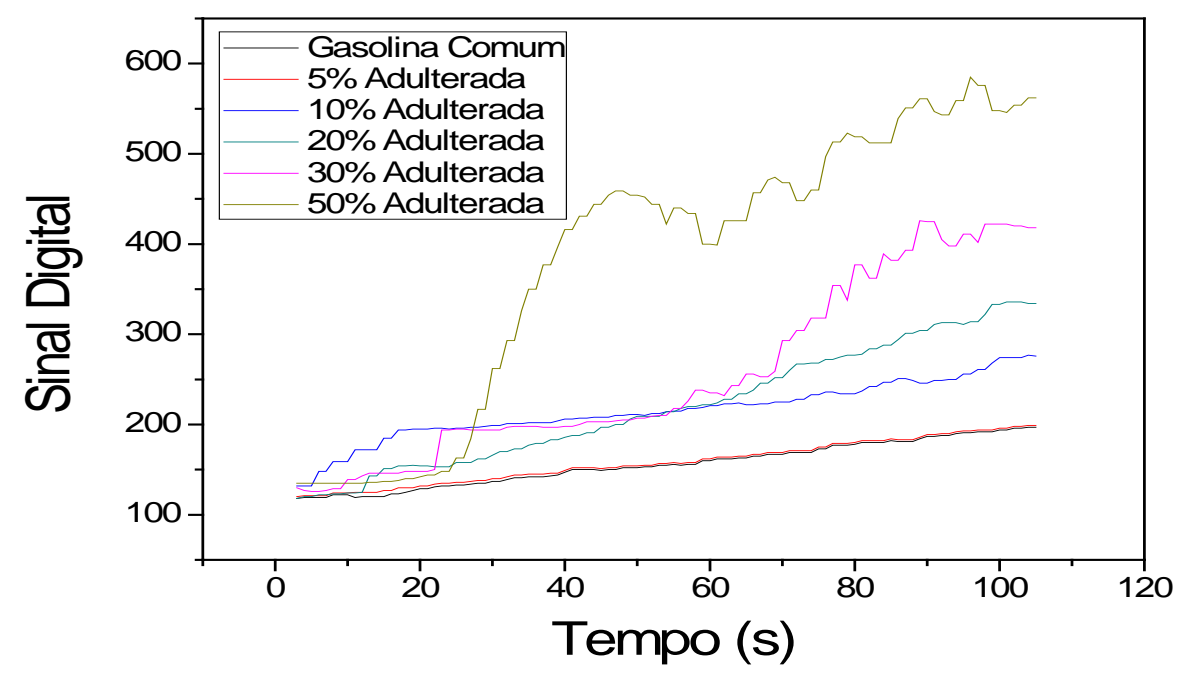

Figura 7. Leitura do sensor MQ-3. 
Com a observação das Figuras 6 e 7 geradas pelas leituras realizadas nos cinco níveis de adulteração do combustível, é possível notar que os sensores conseguiram captar as diferenças de composição (adulteração) entre as amostras analisadas. Desde percentuais pequenos de adulteração como 5\% de adição do etanol anidro na gasolina comum.

As curvas geradas demonstram que a partir de $80 \mathrm{~s}$ de teste os sensores conseguem detectar de maneira satisfatória a adulteração do combustível em todos os percentuais de adição de etanol anidro avaliado no presente estudo. As figuras referentes aos demais sensores utilizados no protótipo não foram aqui avaliadas, pois tais sensores não são específicos para detecção de presença de etanol, sendo utilizados para outras aplicações do protótipo.

Desta forma, foi possível atestar que a matriz de sensores associada a uma programação e a uma análise superficial são ferramentas razoávelmente suficientes para a detecção desse tipo de adulteração na gasolina comum. Esta detecção pode ser feita criando padrões de gráficos de leituras realizadas em combustíveis que estejam dentro dos limites estabelecidos pela ANP, e comparando-os com os testes realizados em amostras colhidas em outras fontes.

\section{Conclusão}

Após as modificações realizadas no protótipo o mesmo se mostrou estável e sem vazamentos e o conjunto de sensores escolhido foi eficiente para identificar as amostras de gasolina adulteradas em todos os percentuais de etanol anidro avaliados. Em apenas $80 \mathrm{~s}$ o protótipo conseguiu detectar diferentes níveis de adulteração do combustível, apresentando-se como uma alternativa rápida, prática e de baixo custo. 0 instrumento poderá ser utilizado no futuro para detecção qualitativa do teor de etanol anidro presente na gasolina e podendo ter o percentual quantitativo estimado criando padrões de gráficos de leituras realizadas em combustíveis que estejam dentro dos limites estabelecidos pela ANP, e comparando-os com os testes realizados em amostras colhidas em postos de combustíveis. Estudos posteriores podem ser realizados visando ao desenvolvimento de metodologia para determinação da adulteração do combustível quantitativamente o que demanda o estudo com redes neurais e não configurava o objetivo do presente trabalho.

\section{Conflitos de interesse}

conflitos de interesse.

0 autor declara não haver

\section{Referências}

ANP - Agência Nacional do Petróleo, Gás Natural e Biocombustíveis. Resolução ANP no 40, de 25 de outubro de 2013. Regula as especificações das gasolinas de uso automotivo, consoante as disposições contidas no Regulamento Técnico no 3/2013, parte integrante desta Resolução, e as obrigações quanto ao controle da qualidade a serem atendidas pelos diversos agentes econômicos que comercializam o produto em todo o território nacional. Disponível em: <http://legislacao.anp.gov.br/?path=legislac ao-anp/resol-anp/2013/outubro\&item= ranp-40--2013>. Acesso em: 09 jun. 2018.

Campos, A. G. Análise da atividade do frentista diante do perigo da exposição ao benzeno. Recife: Fundação Oswaldo Cruz. Instituto Aggeu Magalhães, 2017. (Tese de Doutorado). Disponível em: <https://www. arca.fiocruz.br/handle/icict/27365>. Acesso em: 09 jun. 2018.

Ferreira, R. L. Análise da influência da adulteração de combustível na degradação do lubrificante e do motor de combustão interna. Ilha Solteira, São Paulo: UNESP, 2017. (Dissertação de mestrado). Disponível em: <https://repositorio. unesp.br/handle/11449/149975>. Acesso em: 16 jun. 2018.

Figueirôa, J. A.; Silva, C. M.; Sousa, A.S. Análise laboratorial do teor de álcool na 
gasolina vendida no Município de FlorestaPE. A Barriguda: Revista Científica, v. 7, n. 1, p.150-162, 2017. https://doi.org/ 10.24864/arepb.v7i1.357

Freitas, L. Avaliação da qualidade da gasolina tipo $\mathrm{C}$ em postos de um Município da Paraíba. Campina Grande: UEPB, 2017. (Trabalho de Conclusão de Curso). Disponível em: <http://dspace.bc.uepb.edu.br/jspui/ handle/123456789/15030>. Acesso em: 15 jun. 2018.

Hygino, B. C.; Fernandes, F. T.; Amaral, I. E. Gasolina adulterada: uma proposta didática com enfoque CTS no ensino de Física e Química. Arraial do Cabo: Instituto Federal de
Educação, Ciência e Tecnologia do Rio de Janeiro, 2016.

Lisboa, H. M.; Page, T.; Guy, C. Gestão de odores: fundamentos do nariz eletrônico. Engenharia Sanitária e Ambiental, v. 14, n. 1, p. 9-18, 2009. https://doi.org/10.1590/ S1413-41522009000100002

Reitenbach, A. Desenvolvimento de nariz eletrônico para detecção de compostos voláteis na cerveja. Florianópolis: Universidade Federal de Santa Catarina, 2016. (Tese de Doutorado). Disponível em: <https://repositorio.ufsc.br/xmlui/handle/1 23456789/176718>. Acesso em: 02 jul. 2018. 